\title{
THE STATE OF THE HR PROFESSION
}

\author{
DAVE ULRICH, JON YOUNGER, WAYNE BROCKBANK, \\ AND MICHAEL D. ULRICH
}

\begin{abstract}
We want to create a new narrative about the human resource (HR) profession. HR professionals have often been plagued with self-doubts, repeatedly re-exploring HR's role, value, and competencies. If HR is to fully (and finally) become a profession, these self-doubts need to be replaced with informed insights. These informed insights should be based more on global data than personal perceptions so that the emerging narrative for the HR profession has both substance and meaning.
\end{abstract}

Keywords: leadership; ethics; training and development; organizational change

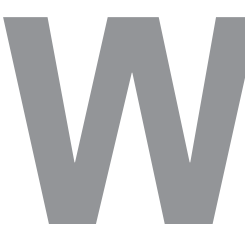

e want to create a new narrative about the human resource (HR) profession. HR professionals have often been plagued by self-doubt, repeatedly re-exploring HR's role, value, and competencies. If $\mathrm{HR}$ is to fully (and finally) become a profession, these self-doubts need to be replaced with informed insights. These informed insights should be based more on global data than personal perceptions so that the emerging narrative for the HR profession has both substance and meaning. Fanning (2011) reports nine characteristics of a profession:

1. Governing body. A profession has an accepted governing body or association.

2. Certification, education, and training. The governing body defines expectations for professionals.

3. Body of knowledge. A profession relies on a base of knowledge and insights that define accepted knowledge.
4. Code of ethics and discipline. A profession imposes accepted standards and conduct for performance.

5. Legal status. A profession has statutory basis within the country.

6. Research. A profession funds future research and helps drive data-based solutions.

7. Independence. Professionals operate independently to serve clients.

8. Contribution to society. A profession contributes to society through certifying members and offering legislative insight.

9. Recognition. A profession is recognized for the quality of work it does.

HR increasingly meets these criteria.

Since 1987, we have done research to further the profession by defining the competencies that explain what makes effective HR professionals personally effective and what HR professionals do to impact business performance. This research has been done in six waves every five years and has resulted 
T A B L E I Historical Overview of HR Competencies Research

\begin{tabular}{|c|c|c|c|c|c|}
\hline & \multicolumn{5}{|c|}{ Five Rounds of Research by Year } \\
\hline & $\begin{array}{c}\text { Round } 1 \\
1987\end{array}$ & $\begin{array}{l}\text { Round } 2 \\
1992\end{array}$ & $\begin{array}{l}\text { Round } 3 \\
1997\end{array}$ & $\begin{array}{l}\text { Round } 4 \\
2002\end{array}$ & $\begin{array}{l}\text { Round } 5 \\
2007\end{array}$ \\
\hline Total Respondents & 10,291 & 4,556 & 3,229 & 7,082 & 10,063 \\
\hline Business Units & 1,200 & 441 & 678 & 692 & 413 \\
\hline Associate Raters & 8,884 & 3,805 & 2,565 & 5,890 & 8,414 \\
\hline HR Participants & 1,407 & 751 & 664 & 1,192 & 1,671 \\
\hline $\begin{array}{l}\text { General } \\
\text { Competence Area }\end{array}$ & \multicolumn{5}{|c|}{$\begin{array}{l}\text { Competency Domains } \\
\text { (Showing the Evolution of the Competencies by Each Round of Study) }\end{array}$} \\
\hline \multirow[t]{2}{*}{ Business } & $\begin{array}{l}\text { Business } \\
\text { knowledge }\end{array}$ & $\begin{array}{l}\text { Business } \\
\text { knowledge }\end{array}$ & $\begin{array}{l}\text { Business } \\
\text { knowledge }\end{array}$ & $\begin{array}{l}\text { Business } \\
\text { knowledge }\end{array}$ & $\begin{array}{l}\text { Business } \\
\text { ally }\end{array}$ \\
\hline & & & & $\begin{array}{l}\text { Strategic } \\
\text { contribution }\end{array}$ & $\begin{array}{l}\text { Strategic } \\
\text { architect }\end{array}$ \\
\hline \multirow[t]{2}{*}{ HR } & HR delivery & HR delivery & HR delivery & HR delivery & $\begin{array}{l}\text { Talent man- } \\
\text { ager and } \\
\text { organization } \\
\text { designer }\end{array}$ \\
\hline & & & & HR technology & $\begin{array}{l}\text { Operational } \\
\text { executor }\end{array}$ \\
\hline Change & Change & Change & Change & In this round & Culture \\
\hline Culture & & & Culture & $\begin{array}{l}\text { change- and } \\
\text { culture-related } \\
\text { competen- } \\
\text { cies were } \\
\text { combined into } \\
\text { strategic con- } \\
\text { tribution }\end{array}$ & $\begin{array}{l}\text { and change } \\
\text { steward }\end{array}$ \\
\hline Personal & & $\begin{array}{l}\text { Personal } \\
\text { credibility }\end{array}$ & $\begin{array}{l}\text { Personal } \\
\text { credibility }\end{array}$ & $\begin{array}{l}\text { Personal } \\
\text { credibility }\end{array}$ & $\begin{array}{l}\text { Credible } \\
\text { activist }\end{array}$ \\
\hline
\end{tabular}

in clarification of roles, standards, and expectations for HR professionals around the world (see Table I for a summary of this research).

In this leadership forum, we highlight our 2012 research that advances the profession by defining standards for HR professionals. ${ }^{1}$ Through previous research, focus groups, theory, and experience, we identified 139 specific behaviors that define what HR professionals should be, know, and do. To determine the degree to which HR professionals demonstrate these competencies, we used a 360-degree-based survey methodology where HR professionals filled out a self-report survey and then invited both HR and non-HR associates to assess their ability to deliver these competencies. In addition, the survey had two outcome variables: personal effectiveness ("Compared to other HR professionals you have known, how does this participant compare?") and business performance using an index of seven dimensions of business success.

The respondent roles for this research include self-report (HR participants), the perception of HR colleagues (HR associates), and those of line managers, peers, and clients (non-HR associates) (see Table II). These data don't just represent HR people talking about what they think matters, but also insights from those outside HR. It is interesting to note that the non-HR respondents are 69 percent male, while the HR respondents are 65 percent female. These data are global 


\begin{tabular}{|c|c|c|}
\hline $\begin{array}{l}\text { Respondent } \\
\text { Role }\end{array}$ & Definition & $\begin{array}{c}N \\
\% \text { Female } \\
\% \text { Male }\end{array}$ \\
\hline All Respondents & $\begin{array}{l}\text { All respondents who completed a majority of } \\
\text { the } 139 \text { competency items }\end{array}$ & 20,013 \\
\hline HR Associates & $\begin{array}{l}\text { All respondents, participants, and associate } \\
\text { raters who work in HR }\end{array}$ & $\begin{array}{c}9,897 \\
\text { F 65\% } \\
\text { M 35\% }\end{array}$ \\
\hline Non-HR Associates & $\begin{array}{l}\text { All respondents and associate raters who are } \\
\text { not part of the HR organization }\end{array}$ & $\begin{array}{c}7,488 \\
F 31 \% \\
M \quad 69 \%\end{array}$ \\
\hline Participants & $\begin{array}{l}\text { HR participants who elected to participate; each } \\
\text { participant has associate raters as well }\end{array}$ & $\begin{array}{c}\mathbf{2 , 6 3 8} \\
\text { F 62\% } \\
\text { M 38\% }\end{array}$ \\
\hline
\end{tabular}

with respondents from every region in the world and comprehensive in that most industries are well represented. This is the largest global, comprehensive, and longitudinal assessment of the HR profession.

These data enable us to answer two questions about the state of the HR profession in this leadership forum:

- What are the personal demographics of HR professionals?

- What are the competencies of HR professionals and how do they affect (1) the perceived effectiveness of HR professionals and (2) business performance?

\section{What Are the Personal Demo- graphics of HR Professionals?}

As indicated earlier, in the 2012 sample, we have demographic data from 2,638 individual HR professionals. With our 25-year study, we can trace the evolution of the HR demographics from 1987 to 2012. Table III reports these results and offers a number of insights:

- Feminization of the profession. In the last 15 years (from 1997 to 2012), the percentage of males in HR has dropped from 70 percent to 38 percent, and females increased from 30 percent to 62 percent. Clearly, women are moving into HR in increasing numbers. This trend is amplified in more recent years from 2007 to 2012 . It is also interesting to note that the non-HR associates are 69 percent males, which means that often female HR professionals are working with male associates.

- Education of HR professionals. Over the 25 years, HR professionals tend to be highly educated. This continues in 2012, with 51 percent of the HR professionals having graduate degrees and 39 percent college degrees. This indicates the high education expectations for HR professionals in today's market. It may also indicate a bias in this sample, being more focused on more educated HR professionals.

- Career patterns for HR professionals. As economic demands force HR to do more with less, and information technology and outsourcing change the size and shape of HR organizations, HR professionals are increasingly individual contributors who offer specialist insights (34 percent). At least according to our longitudinal research, HR careers may more likely be within a functional specialty than leadership roles in HR. We may infer that, to a significant extent, this is associated with increasing spans of control, and reduced layers, within HR.

- Years in HR profession. In the last 15 years, we have found an increasing number of HR professionals in HR positions less than 5 years (25 percent). This may indicate the growth of the HR profession or it 


\begin{tabular}{|c|c|c|c|c|c|c|}
\hline Round & $\begin{array}{c}\text { Round } 1 \\
1987\end{array}$ & $\begin{array}{c}\text { Round } 2 \\
1992\end{array}$ & $\begin{array}{c}\text { Round } 3 \\
1997\end{array}$ & $\begin{array}{c}\text { Round } 4 \\
2002\end{array}$ & $\begin{array}{l}\text { Round } 5 \\
2007\end{array}$ & $\begin{array}{c}\text { Round } 6 \\
2012\end{array}$ \\
\hline \multicolumn{7}{|l|}{ Gender of HR Participant } \\
\hline - Male & $77 \%$ & $78 \%$ & $70 \%$ & $57 \%$ & $46 \%$ & $38 \%$ \\
\hline - Female & 23 & 22 & 30 & 43 & 54 & 62 \\
\hline \multicolumn{7}{|l|}{ Education of HR Participant } \\
\hline - High school degree & $3 \%$ & $7 \%$ & $4 \%$ & $4 \%$ & $9 \%$ & $3 \%$ \\
\hline - Associate college degree & 5 & 7 & 6 & 9 & 12 & 7 \\
\hline - Bachelor's degree & 48 & 43 & 42 & 42 & 37 & 39 \\
\hline - Graduate degree & 44 & 43 & 48 & 45 & 41 & 51 \\
\hline \multicolumn{7}{|l|}{ Level of the HR Participant } \\
\hline - Individual contributor & $20 \%$ & $24 \%$ & $29 \%$ & $24 \%$ & $28 \%$ & $34 \%$ \\
\hline $\begin{array}{l}\text { - Manager of individual } \\
\text { contributors }\end{array}$ & 36 & 41 & 34 & 34 & 30 & 39 \\
\hline - Director of managers & 36 & 29 & 30 & 31 & 20 & 19 \\
\hline - Top manager & 8 & 6 & 7 & 11 & 21 & 7 \\
\hline \multicolumn{7}{|l|}{ Years in HR for HR Participant } \\
\hline - 5 years or less & $10 \%$ & $14 \%$ & $13 \%$ & $25 \%$ & $24 \%$ & $25 \%$ \\
\hline - 6-9 years & 14 & 19 & 15 & 18 & 20 & 18 \\
\hline - 10-14 years & 26 & 24 & 21 & 22 & 23 & 25 \\
\hline - 15 or more years & 50 & 43 & 51 & 35 & 32 & 32 \\
\hline \multicolumn{7}{|l|}{ Primary Role of HR Participant } \\
\hline - Benefits/medical/safety & $6 \%$ & $5 \%$ & $5 \%$ & $4 \%$ & $3 \%$ & $3 \%$ \\
\hline - Compensation & 5 & 4 & 4 & 6 & 6 & 7 \\
\hline $\begin{array}{l}\text { - HR planning/strategy/ } \\
\text { affirmative action }\end{array}$ & 6 & 8 & 5 & 8 & 14 & 14 \\
\hline - Labor relations & 6 & 8 & 5 & 6 & 5 & 4 \\
\hline $\begin{array}{l}\text { - Org. development/research/ } \\
\text { effectiveness }\end{array}$ & 2 & 5 & 3 & 13 & 7 & 9 \\
\hline - Recruiting & 3 & 6 & 4 & 4 & 6 & 11 \\
\hline - Training/communication & 7 & 14 & 6 & 12 & 9 & 11 \\
\hline - Generalist & 61 & 45 & 60 & 48 & 49 & 40 \\
\hline
\end{tabular}

may indicate the trend to move people across organization functions for career purposes.

- Role of HR professionals. In the last 5 years, there has been a drop in the percentage of HR professionals who are generalists (49 percent to 40 percent) rather than specialists. Recruiting is the area of increased specialization that may indicate the increased attention to talent and human capital. ${ }^{2}$

The overall takeaway of Table III is that the demographics of being an HR professional continue to evolve to match changing business conditions.

\section{What Are the Competencies of HR Professionals and How Do They Af- fect (1) the Perceived Effectiveness of HR Professionals and (2) Business Performance?}

As early as the mid-1980s, the American Society for Training and Development (ASTD) sponsored Patricia McLagan in her efforts to 
identify competencies for HR training and development professionals (McLagan, 1996). Her work subsequently broadened to include all HR professionals (McLagan \& Bedrick, 1983; see also McLagan \& Suhadolnik, 1989). Around the same time, a number of large companies began creating their own internal HR competency models. Out of these independent efforts grew many frameworks for HR competencies, but there were relatively few efforts to document professional HR competencies across firms, industries, or geographies. The profession needed a competency modela set of expectations for those who work in HR and a basis for assessment and improvement in the quality of HR professionals.

When we began our HR competencies study in 1987, we wanted to define these competencies less by self-report of HR professionals and more by how others perceived the HR professionals. We also wanted to show the impact of HR competencies on how others perceived the individual effectiveness of HR professionals and how HR professionals impacted their business performance. This work resulted in the five waves of data collection reported in Table I. These studies have resulted in several doctoral dissertations, several books, dozens of chapters, and dozens of articles. ${ }^{3}$ They have helped to shape how effective HR professionals think and behave over the past 25 years. In recent years, many have built on this work to define competencies for HR professionals.

Wright, Stewart, and Moore of Cornell Advanced HR Studies (CAHRS) surveyed 56 chief HR officers (CHROs) in 2009, 72 in 2010, and 172 in 2011 (Wright, Stewart, \& Moore, 2011). For the 2011 data, both European and US CHROs suggested talent as the most critical challenge, followed by cost control, succession planning, culture, and employee engagement (responses vary somewhat by European vs. US CHROs). They also found that building HR competencies is the largest obstacle to achieving the CEO's agenda for HR. The practices most likely used to increase CHRO effectiveness are: learning from an external network, business focus, self-development activities, and effective HR processes. They also identified eight roles for
CHROs and time spent on each role: strategic advisor, counselor/confidant/coach, board liaison, talent architect, HR function leader, workforce sensor, and firm representative.

Boston Consulting Group has done annual studies of the HR profession in collaboration with the World Federation of People Management Associations and European Association of People Management Associations (see Caye \& Strack, 2009; Strack et al., 2011). In their 2011 study, they received surveys from 2,039 executives in 35 European countries. Based on executive assessments of "current capability" and "future importance," the four most critical topics for HR were (1) managing talent (recruiting, development, retention), (2) improving leadership development, (3) transforming HR into being a strategic partner, and (4) strategic workforce planning. They identified five critical HR capabilities (competencies) to address these topics: transforming HR into a strategic partner, mastering HR processes, delivering on recruiting, restructuring the organization, and improving leadership development. They also highlighted the importance of technology and social media.

The Center for Effective Organizations (CEO) has studied HR effectiveness over the past number of years. ${ }^{4}$ In their recent work based on their experiences, they suggest six trends or shifts facing HR professionals:

- hero leadership to collective leadership,

- intellectual property to agile co-creativity,

- employment value proposition to personal value proposition,

- sameness to segmentation,

- fatigue to sustainability, and

- persuasion to education.

They suggest that these six themes need to respond to external trends as well as organization processes. They then propose HR structure and competency changes to respond to these trends.

Deloitte, a consulting firm, summarizes their recommendations for HR competencies into three broad requirements: (1) business (commercial awareness, business acumen, customer focus, aligned business to HR), (2) HR (employee relations, get the basics right, HR expertise, HR metrics, change delivery), 
and (3) consulting capabilities (brokering, trusted advisor, impact and influence, facilitation and coaching, leadership, project delivery) (Deloitte, 2011). They argue that when HR professionals master these competencies, they are able to be business partners who help their business be successful. They base their recommendations on case experiences with their clients.

Hewitt, another consulting firm, surveyed 85 individuals to find out how these 85 firms managed their human resource priorities and competencies (Hewitt, 2009). They suggested that HR professionals needed competencies in organization design, service delivery/technology, governance/metrics, strategy, and program design. When HR professionals master these four skill sets, they are able to help their companies manage their businesses.

Roffey Park Institute, a research institute in London, surveyed $171 \mathrm{HR}$ professionals and interviewed seven subject-matter competencies as seen by oneself and others affect both perceived personal

effectiveness and business

performance. success.

The Society for Human Resource Management (SHRM) has held a number of forums on the future of HR (see, e.g., SHRM, 2005). ${ }^{5}$ By talking with HR leaders, they propose that HR professionals should learn the business, be willing to change, use more analytics, find and develop talent, show greater personal initiative, have discipline in execution, prioritize better, and become accountable for results. Their HR competency work focuses on behavioral descriptors of what HR professionals believe they need to know and do to be effective.
The Chartered Institute of Personnel and Development (CIPD) has created an HR profession map that offers a comprehensive view of how HR professionals can provide insights and solutions to their businesses. ${ }^{6}$ This map is organized around how HR can provide leadership and insights around eight HR practice areas: organization design, organization development, resourcing and talent planning, learning and talent development, performance and rewards, employee engagement, employee relations, service delivery, and information.

\section{Summary}

Most of these approaches to HR competencies rely on self-perception by asking HR professionals to report on what they think they need to know and do in order to be effective. Our research explores how HR competencies as seen by oneself and others affect both perceived personal effectiveness and business performance. For our 2012 round of data collection, we identified 139 specific behavioral competencies derived from the previous five rounds of data collection and from dozens of focus groups in which we identified current business trends that require new HR competencies. As indicated earlier, we then collected data from HR participants $(2,638)$ and from associates inside HR $(9,897)$ and outside HR $(7,488)$ on the extent to which the HR participants demonstrated these competencies.

We then utilized factor analysis to cluster these 139 competencies into six domains of HR competencies. A total of 138 of the 139 items loaded .4 or higher, which led to the six domains (the details of the factor analyses are available from the authors). We then identified 20 factors within the six domains through secondary factor analysis. These six domains of HR competence are described in the paragraphs that follow, both in terms of what HR should focus on (e.g., strategy, HR, change) and how HR should focus on that area through specific HR roles (e.g., positioner, champion, builder, innovator, integrator). These six domains define the skills and knowledge that HR professionals should demonstrate. 
Strategic Positioner. High-performing HR professionals think and act from the outside-in by mastering four levels of business. First, they learn the language of the business, which revolves around finance. Like learning a foreign language, they may not speak like a native, but they need to be able to get around. Second, they need to co-create their organization's strategy. Third, they need to target and serve key customers of their organization by identifying customer segments, knowing customer expectations, and aligning organization actions to meet customer needs. Finally, they need to be deeply knowledgeable of general business conditions (e.g., social, technological, economic, political, environmental, and demographic trends) that affect their respective industries and geographical regions.

Credible Activist. Effective HR professionals are credible activists because they build their personal trust through business acumen. Credibility comes when HR professionals do what they promise, build personal relationships of trust, and can be relied on. They communicate clear and consistent messages with integrity. They also have a point of view, not only about HR activities, but also about business demands. They learn how to influence others in a positive way through clear, consistent, and high-impact communications. Finally, HR professionals need to be self-aware and committed to building their profession.

Capability Builder. An effective HR professional melds individual abilities into effective organization capabilities. Capability represents what the organization is good at and known for that represents an organization's institutional strengths and the reputation that the organization has relative to those strengths. Capabilities have been referred to as a company's culture, process, or identity. HR professionals should facilitate capability audits to determine the identity of the organization. Such capabilities include customer service, speed, quality, efficiency, innovation, and collaboration. One such emerging capability of successful organizations is to create an organization where employees find meaning and purpose at work.
Change Champion. As change champions, HR professionals make sure that isolated and independent organization actions are integrated and sustained through disciplined change processes. HR professionals make an organization's internal capacity for change match or lead the external pace of change. As change champions, HR professionals help make change happen at institutional (changing patterns), initiative (making things happen), and individual (enabling personal change) levels. To make change happen at these three levels, HR professionals play two critical roles in the change process. First, they initiate change by building a case for why change matters, overcoming resistance to change, engaging key stakeholders in the process of change, and articulating the decisions to start change. Second, they sustain change by institutionalizing change through ensuring organizational resources, designing organization structures, facilitating systemic communications, and orchestrating continual learning.

Human Resource Innovator and Integrator. Effective HR professionals know the historical research on HR so that they can be innovative and integrate HR practices into unified solutions to solve future business problems. They must know the latest insights on key HR practice areas related to human capital (talent sourcing, talent development), performance accountability (appraisal, rewards), organization design (teamwork, organization development), and communication. They must also be able to turn these unique HR practice areas into integrated solutions, generally around an organization's leadership brand. These innovative and integrated HR practices then result in high impact on business results by ensuring that HR practices maintain their focus over the long run and do not become seduced by HR "flavor the month" or by another firm's "best practices."

Technology Proponent. In recent years, technology has changed the way in which HR people think and do their administrative and strategic work. At a basic level, HR professionals need to use technology to more efficiently deliver HR administrative systems such as benefits, payroll processing, 


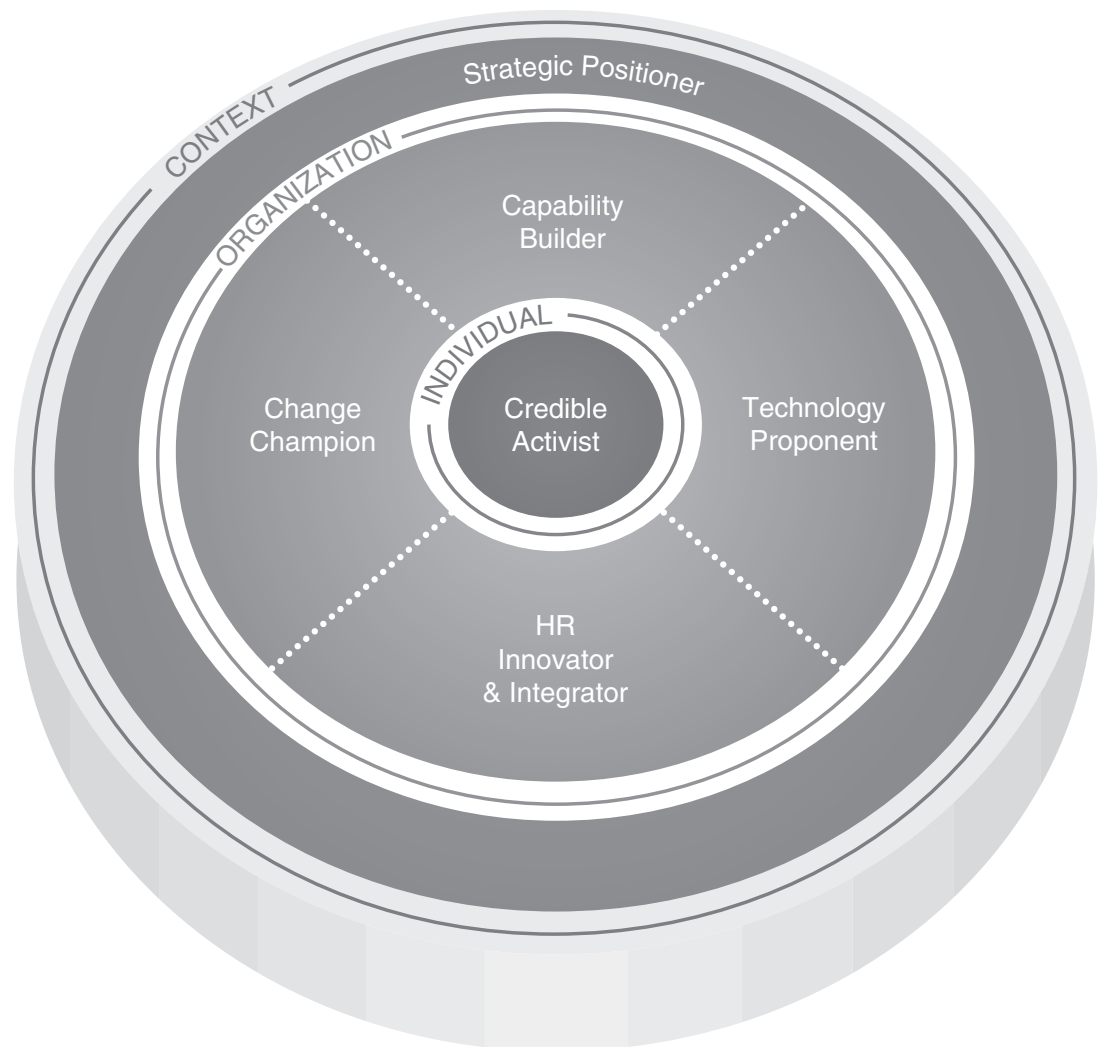

FIGURE 1. 2012 HR Competencies for the Future

health care costs, and other administrative services. In addition, HR professionals need to use technology to help people stay connected with one another. This means that technology plays an increasingly important role in improving communications, doing administrative work more efficiently, and connecting inside employees to outside customers. An emerging technology trend is using technology as a relationship-building tool through social media. Leveraging social media enables the business to position itself for future growth. HR professionals who understand technology will create improved organizational identity outside the company and improve social relationships inside the company. As technology proponents, HR professionals have to access, advocate, analyze, and align technology for information, efficiency, and relationships.

As Figure 1 suggests, we view these six domains of HR competence operating in three spheres of influence:
- Context. HR professionals work from the outside-in. They help define their organization's strategic position by understanding general business contexts and specific stakeholder expectations. They turn these external factors into internal strategy, capabilities, and investments. As we have said elsewhere, the HR role is to look "through" the mirror of strategy to help shape strategic needs.

- Organization. HR professionals create strong organizations. HR high performers convert context into a framework of action and organizational discipline by building capability, leading change, innovating and integrating $\mathrm{HR}$ practices, and proposing technology initiatives that improve effectiveness and efficiency.

- Individual. HR professionals attend to individuals, both themselves and employees throughout their organizations. Strong HR professionals operate at a personal level as credible activists, who build relationships 


\begin{tabular}{|c|c|c|c|}
\hline \multirow[t]{2}{*}{ TA B LE IV } & \multirow[b]{2}{*}{$\begin{array}{c}\text { Column I } \\
\text { Mean Score on This } \\
\text { Competence Domain }\end{array}$} & \multirow[b]{2}{*}{$\begin{array}{c}\text { Column II } \\
\text { Impact on Perception } \\
\text { of HR Effectiveness } \\
\text { (Beta Weights Scaled } \\
\text { to } 100 \%)^{b}\end{array}$} & \multirow[b]{2}{*}{$\begin{array}{c}\text { Column III } \\
\text { Impact on Business } \\
\text { Performance } \\
\text { (Beta Weights Scaled } \\
\text { to } 100 \% \text { ) }\end{array}$} \\
\hline & & & \\
\hline Credible Activist & 4.23 & $22 \%$ & $14 \%$ \\
\hline Strategic Positioner & 3.89 & $17 \%$ & $15 \%$ \\
\hline Capability Builder & 3.97 & $16 \%$ & $18 \%$ \\
\hline Change Champion & 3.93 & $16 \%$ & $16 \%$ \\
\hline $\begin{array}{l}\text { Human Resource Innovator } \\
\text { and Integrator }\end{array}$ & 3.90 & $17 \%$ & $19 \%$ \\
\hline \multirow[t]{2}{*}{ Technology Proponent } & 3.74 & $12 \%$ & $18 \%$ \\
\hline & & Multiple $R^{2} 42.5 \%$ & $8.4 \%$ \\
\hline
\end{tabular}

aln this table, we report the overall findings. We have analyzed the results by geographic region, years in HR, level in HR, position, gender, and time in position. The same general pattern occurs for each subcategory, which suggests that these findings offer a baseline for the profession.

${ }^{\mathrm{b} T o}$ explain the relative impact of these six competencies on HR personal effectiveness and business performance, we did multiple regressions. The beta weights derived from these regressions were then scaled to 100 points to help translate the results to a professional, not academic audience. Beta weights and all other statistics are available from the authors.

of trust so that they can advocate for both personal and business results.

We then identified the impact of these six domains on both the perception of the effectiveness of the HR professional and the performance of the business where the HR professional works (see Table IV and Figure 1).

From Column I of Table IV, we assess in which of the HR competency domains HR professionals tend to perform best:

- HR professionals function best in the domain as credible activists. They are effective at building their credibility by establishing relationships of trust, by effectively communicating key business and HR issues, and by actively advocating insightful opinions that move the business forward.

- They perform the core of the competency domains at a somewhat lower level of effectiveness. They contribute to the establishment of a customer-focused business strategy; they translate the business strategy into important organizational capabilities; they build and sustain organizational capabilities through the disciplined and integrated application of HR innovations; and they create organizations that are flexible and adaptable at achieving business results.

- The domain in which HR tends to be the weakest is in understanding and applying technology to build HR efficiency, to leverage social networking, and to manage the flow of strategic information.

\section{Which Competencies Have Greatest Impact on Individual Performance of HR Professionals as Perceived by Their Line and HR Associates?}

In Column II of Table IV, we identify the relative impact of the six competency domains on the overall competence of HR professionals as seen by their respective HR and non-HR associates. To be perceived as a competent HR professional, the HR professional should focus on the following:

- Most important is for HR professionals to exhibit the competencies of a credible activist as described earlier.

- The other core HR activities are closely bundled together. This implies that to be seen as an overall competent HR professional, HR 
professionals must exhibit the core HR competency domains in an integrated manner.

- Excelling as a technology proponent has the least influence on the associates' perceptions of HR professionals. This may partially be due to low expectations and lack of experience that HR professionals have in this domain.

\section{Which Competencies Have Greatest Impact in Differentiating HR Profes- sionals in High-Performing Firms From Those in Low- Performing Firms?}

From Column III of Table IV, interesting and, to some degree, unexpected results are expressed.

The close results of

HR as a capability

- The close results of HR as a capability builder (18 percent) and

builder (18 percent) HR innovator and integrator (19 percent) reinforce the logic that and HR innovator HR practices must integrate to create and sustain key organizational and integrator (19 percent) reinforce the logic that $H R$ practices must integrate to create and sustain key organizational capabilities in order to significantly impact business performance. capabilities in order to significantly impact business performance.

- The impact on business performance of HR as a technology proponent is at a level that is at the same level of impact as HR as a capability builder and as an HR innovator and integrator. This is a remarkable and unexpected finding. It suggests that for HR professionals to drive business performance, they need to master technology and information.

To offer additional insights of what makes an effective HR professional, we look at 20 subfactors that characterize the competencies of HR professionals (see Table $\mathrm{V)}$.

For the strategic positioner domain, co-crafting the strategic agenda is most important for being seen by associates as a competent contributor. However, decoding customer expectations has greater impact on business performance.

Virtually all of the credible activist activities subfactors are done at a relatively high level and have the greatest impact on individual effectiveness. But they systematically have much less impact on business performance.

For the capability builder domain, capitalizing on organizational capability and creating a meaningful work environment have an average impact on business performance, but aligning strategy, culture, behavior, and practices has the second-greatest impact on business performance of any of the subfactors, and it is done at a modest level of effectiveness. This indicates an obvious area for HR to focus its efforts.

The change champion domain results at the subfactor level are likewise interesting. To be seen as a competent individual contributor, the HR professional should initiate change. However, to contribute to business performance, sustaining change is more important.

The HR innovator and integrator domain has substantial influence on both individual effectiveness and business performance. The average influence of its subfactors on business performance is the highest among all domains. Its subfactors are second only to the credible activist subfactors in influence on individual effectiveness. The subfactors have similar influence on business performance. The data suggest that HR professionals must make sure that their collective practices are innovative and integrated.

The subfactor analyses for the technology proponent domain show that average individual effectiveness scores of these subfactors are the lowest among all domains. Yet the collective impact of these subfactors on business performance is second only to the influence of the collective subfactors of the HR innovator and integrator on business performance. And the subfactor, connecting people through technology, has more influence on business performance than any other subfactor across all domains. This rather remarkable finding is profound. In today's information-intensive world, HR professionals in high-performing firms are becoming masters at managing the message. They are excelling at connecting stakeholders 


\begin{tabular}{|c|c|c|c|}
\hline $\begin{array}{l}\text { Subfactor for the Six HR Competency } \\
\text { Domains }\end{array}$ & $\begin{array}{l}\text { Mean } \\
\text { (1 to } 5)\end{array}$ & $\begin{array}{c}\text { Individual } \\
\text { Effectiveness } \\
\text { (Beta Weights } \\
\text { Scaled to } 100 \% \text { ) }\end{array}$ & $\begin{array}{c}\text { Business } \\
\text { Performance } \\
\text { (Beta Weights Scaled } \\
\text { to } 100 \% \text { ) }\end{array}$ \\
\hline \multicolumn{4}{|l|}{ Strategic Positioner } \\
\hline - Interpreting global business context & 3.83 & 4.4 & 4.2 \\
\hline - Decoding customer expectations & 3.83 & 4.4 & 5.2 \\
\hline - Co-crafting a strategic agenda & 3.96 & 6.3 & 4.6 \\
\hline \multicolumn{4}{|l|}{ Credible Activist } \\
\hline - Earning trust through results & 4.36 & 6.9 & 4.0 \\
\hline - Influencing and relating to others & 4.24 & 7.0 & 4.1 \\
\hline - Improving through self-awareness & 4.08 & 6.5 & 4.7 \\
\hline - Shaping the HR profession & 4.13 & 4.4 & 2.9 \\
\hline \multicolumn{4}{|l|}{ Capability Builder } \\
\hline - Capitalizing organizational capability & 4.03 & 5.4 & 5.3 \\
\hline $\begin{array}{l}\text { - Aligning strategy, culture, practices, and } \\
\text { behavior }\end{array}$ & 3.94 & 5.3 & 6.1 \\
\hline - Creating a meaningful work environment & 3.94 & 4.1 & 5.2 \\
\hline \multicolumn{4}{|l|}{ Change Champion } \\
\hline - Initiating change & 3.94 & 5.4 & 4.8 \\
\hline - Sustaining change & 3.91 & 4.7 & 5.7 \\
\hline \multicolumn{4}{|l|}{ HR Innovator and Integrator } \\
\hline $\begin{array}{l}\text { - Optimizing human capital through } \\
\text { workforce planning and analytics }\end{array}$ & 3.95 & 5.5 & 5.6 \\
\hline - Developing talent & 3.83 & 4.0 & 5.3 \\
\hline $\begin{array}{l}\text { - Shaping organization and } \\
\text { communication practices }\end{array}$ & 3.94 & 5.8 & 5.6 \\
\hline - Driving performance & 3.87 & 4.7 & 5.2 \\
\hline - Building leadership brand & 3.87 & 4.9 & 5.4 \\
\hline \multicolumn{4}{|l|}{ Technology Proponent } \\
\hline - Improving utility of HR operations & 3.72 & 2.9 & 5.0 \\
\hline - Connecting people through technology & 3.77 & 4.6 & 6.3 \\
\hline - Leveraging social media tools & 3.68 & 2.7 & 4.7 \\
\hline Overall $R^{2}$ & & .431 & $.108^{\mathrm{a}}$ \\
\hline
\end{tabular}

${ }^{a}$ The slight differences in $R^{2}$ are because the data are factored into either 6 or 20 scales, which shifts somewhat the variance explained, but the ratios are similar with regressions of either 6 or 20 items.

on the outside with people on the inside in meaningful ways through technology.

These results may be further summarized by Figure 2 .

This matrix provides a vivid representation of the relationship between current HR effectiveness and business performance. Note that the personal credibility subfactors are in the upper-left-hand corner, indicating that they are done at a high level of effectiveness but have less influence on business performance. HR professionals should therefore be cautious in continuing to focus on building additional strength in personal credibility. 


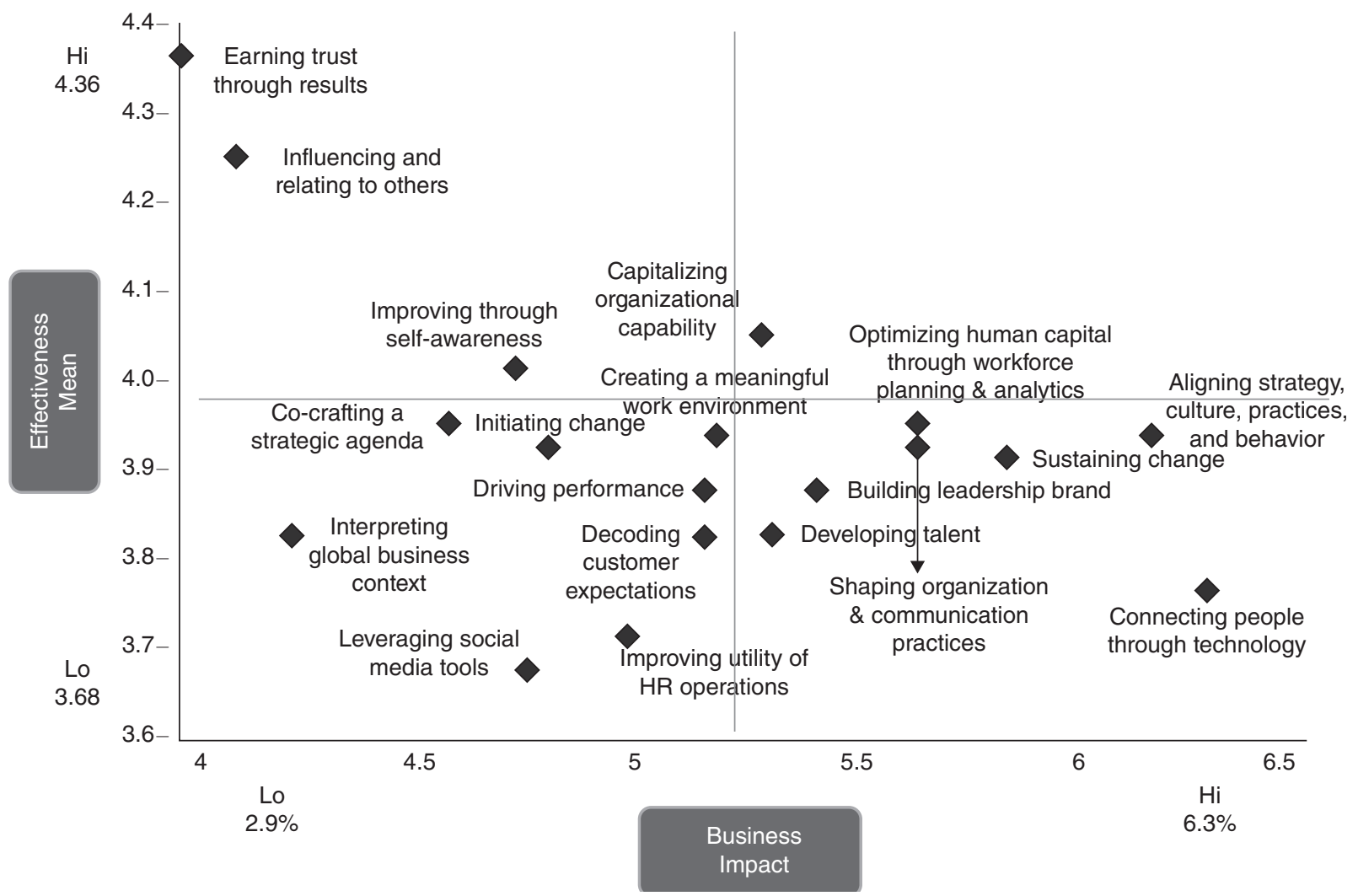

FIGURE 2. Prioritizing HR Competency Actions

Our data indicate that they need to move on to the agendas that add greater value. As indicated earlier, the seductive danger is that while being a credible activist has the lowest impact on business performance, it has the highest impact on being seen as being effective by others. Thus, the knowledge, skills, and abilities that create the appearance of competence are not what actually create business performance.

The subfactors that have the greatest impact on business performance are, in order of importance:

- connecting people though technology;

- aligning strategy, culture, practices, and behavior; and

- sustaining change.

Furthermore, HR professionals exhibit these competencies at medium to low levels of effectiveness. The opportunity for HR professionals to add the greatest value to their organization's success is by focusing on these three, but all the subfactors in the bottom-right cell would be areas of emphasis.

\section{Conclusions and Implications}

The HR profession has arrived. The lingering self-doubts can and should be replaced with self-confidence. The informed insights from this study offer global standards for what HR professionals should be, know, and do. These standards should impact hiring, orienting, promoting, training, and assessing HR professionals. With these insights, we are confident that an emerging narrative about HR will help HR professionals be personally effective and favorably impact business performance. 


\section{Notes}

1. In this study, we partnered with the leading HR professional associations in Australia (AHRI), China (jobs51), India (NHRD), Latin America (IAE), Middle East (ASHRM), Northern Europe (HR Norge), South Africa (IPM), and our own extensive networks in North America, including the Ross School of Business at the University of Michigan. These thought and research partners were the foundation for the success of this work.

2. The focus on human capital and talent can be seen in work by:

Boudreau, J. (2010). Retooling HR: Using proven business tools to make better decisions about talent. Boston, MA: Harvard Business School.

Boudreau, J. (2011). Transformative HR: How great companies use evidence based change for sustainable advantage. Boston, MA: Harvard Business School.

Boudreau, J., \& Ramstad, P. (2007). Beyond HR:The new science of human capital. Boston, MA: Harvard Business School.

Cappelli, P. (2008). Talent on demand: Managing talent in an age of uncertainty. Boston, MA: Harvard Business School.

Conaty, B., \& Charan, R. (2010). The talent masters: Why smart leaders put people before numbers. New York, NY: Crown Business.

3. Some of the work includes:

Brockbank, W. (1997). HR's future on the way to a presence. Human Resource Management Journal, $36,65-70$.

Brockbank, W., \& Ulrich, D. (2003). Competencies for the new HR: Society for Human Resource Management. Ann Arbor, MI: University of Michigan Business School, Global Consulting Alliance.

Brockbank, W., Ulrich, D., \& Beatty, D. (1999). The professional development: Creating the future creators at the University of Michigan Business School. Human Resource Management, 38, 111-118.

Brockbank, W., Ulrich, D., \& James, C. (1997).Trends in human resource competencies. Ann Arbor, MI: University of Michigan Business School.

Ulrich, D. (1992). Strategic and human resource planning: Linking customers and employees. Human Resource Planning, 15(2), 47-62.
Ulrich, D. (1993). Profiling organizational competitiveness: Cultivating capabilities. Human Resource Planning, 16(3), 1-17.

Ulrich, D. (1997). HR of the future: Conclusions and observations. Human Resource Management Journal, 36, 175-179.

Ulrich, D. (1997). Human resource champions: The next agenda for adding value and delivering results. Cambridge, MA: Harvard Business Press.

Ulrich, D. (1998). A new mandate for human resources. Harvard Business Review, 76(1), 124-134.

Ulrich, D., Brockbank, W., \& Yeung, A. (1989, November). Human resource competencies in the 1990's: An empirical assessment of what the future holds. Personnel Administrator, pp. 91-93.

Ulrich, D., Brockbank, W., \& Yeung, A. (1990). Beyond belief: A benchmark for human resources. Human Resource Management, 28, 311-335.

Ulrich, D., Brockbank, W., Yeung, A., \& Lake, D. (1995). Human resource competencies and empirical assessment. Human Resource Management, 34, 473-496.

Ulrich, D., Johnson, D., Brockbank, W., Younger, J., \& Sandholtz, K. (2009). HR competencies. Washington, DC: SHRM

Ulrich, D., \& Yeung, A. (1989, March). Human resources as a shared mindset. Personnel Administrator, pp. 38-45.

Ulrich, D., Yeung, A., \& Brockbank, W. (1990). Human resources in the 1990's: Forging personal competencies into functional capability. New York, NY: Simon \& Schuster

Yeung, A., Brockbank, W., \& Ulrich, D. (1994). Lower cost, higher value: Human resources function in transition. Human Resource Planning Journal, 17(3), 1-16.

Yeung, A., \& Ulrich, D. (1990). Effective human resource practices for competitive advantages: An empirical assessment of organizations in transition. In R. J. Niehaus \& K. F. Price (Eds.), Human resource strategies for organizations in transition (pp. 311326). New York, NY: Plenum.

Yeung, K. O. (1990). Cognitive consensuality and organizational performance: A systematic assessment (Unpublished doctoral dissertation) University of Michigan, Ann Arbor, MI. 
4. The work by the Center for Effective Organizations can be referenced on their website: http://ceo.usc.edu/. See also the following:

Boudreau, J., \& Ziskin, I. (2011). The future of HR and effective organizations. Organizational Dynamics, 40, 255-266.

Lawler, E., \& Boudreau, J. (2009). Achieving excellence in human resources management: An assessment of human resource functions. Palo Alto, CA: Stanford University Press.
Lawler, E. (2012). Effective human resource management: A global analysis. Palo Alto, CA: Stanford University Press.

5. See, for example, the SHRM 2005 symposium on the future of strategic HR, www.shrm.org/trends /SympFutureofHR.pdf

6. The CIPD professional map can be found on their website: www.cipd.co.uk/cipd-hr-profession/hr -profession-map/professional-areas/

DAVE ULRICH is a professor in the Ross School of Business at the University of Michigan and a partner at the RBL Group. He has written 25 books and over 200 articles. He has numerous awards for insights on HR, talent, leadership, and organization capabilities. He has also done extensive advisory work for most of the Fortune 200.

JON YOUNGER is partner emeritus at RBL Group and works with a variety of leading global clients in creating more impactful, professional, and strategic HR functions. He is coauthor of four books on HR competence and transformation, and many book chapters and articles. Prior to working at the RBL Group, he was senior vice president and chief talent and learning officer for a large US financial services organization. He has taught in the executive education faculties of the University of Michigan and the Indian School of Business, and for many corporate and governmental organizations. His PhD is from the University of Toronto.

WAYNE BROCKBANK is a clinical professor of business in the University of Michigan's Ross School of Business. He is a core instructor of Michigan's Advanced Human Resource Executive Program, the world's number-one-rated HR executive program. His research focuses on linkages between business strategy and human resource practices, creating high-performance corporate cultures and organization levers that drive business performance. He has consulted on these topics with leading companies on every continent.

MICHAEL D. ULRICH is a doctoral student in the Darla Moore School of Business at the University of South Carolina. His research interests include human capital, SHRM, business strategy, and positive organizational scholarship. Prior to his doctoral studies he worked as a research associate for the RBL Group. He holds a BS and MS in statistics from Brigham Young University.

\section{References}

Caye, J.-M., \& Strack, R. (2009). Creating people advantage in times of crisis: How to address HR challenges in the recession. Boston, MA: Boston Consulting Group.

Deloitte. (2011). Business driven HR: Unlock the value of HR business partners. London, UK: Deloitte.

Fanning, B. (2011). Human resource management: The road to professionalization in the UK and USA (Unpublished master's thesis). Kingston University, London, UK.
Griffin, E., Finney, L., Hennessy, J., \& Boury, D. (2009). Maximising the value of $\mathrm{HR}$ business partnering: A practical research based guide. Horsham, UK: Roffey Park Institute.

Hewitt. (2009). Managing HR on a global scale. London, UK: Aon Hewitt.

McLagan, P. (1996). Great ideas revisited. Training and Development, 50, 60-64.

McLagan, P., \& Bedrick, D. (1983). Models for excellence: The results of the ASTD training and development study. Training and Development, 37, 10-20. 
McLagan, P., \& Suhadolnik, D. (1989). Models for HRD practice:The research report. Alexandria, VA: American Society forTraining and Development.

Society for Human Resource Management (SHRM). (2005). The SHRM symposium on the future of strategic HR. Retrieved from http://www.shrm .org/Research/FutureWorkplaceTrends/Documents /SympFutureofHR.pdf
Strack, R., Caye, J.-M., Teichmann, C., Haen, P., Frick, G., \& Bird, S. (2011). Creating people advantage in times of crisis: Time to act: HR certainties in uncertain times. Boston, MA: Boston Consulting Group.

Wright, P., Stewart, M., \& Moore, O. A. (2011). The 2011 $\mathrm{CHRO}$ challenge: Building organizational, functional, and personal talent. Ithaca, NY: Cornell Center for Advanced Human Resource Studies. 